\title{
Word formation is syntactic: Raising in nominalizations
}

\author{
Benjamin Bruening \\ University of Delaware \\ 125 E. Main Street, Newark DE 19716 USA \\ bruening@udel.edu
}

\section{Appendix: Experimental items for the acceptability survey}

1. (a) (Subj_Nom) According to historians, that radical group was eager to start a civil war despite its certainty to cause a bloodbath.

(b) (Subj_Clause) According to historians, that radical group was eager to start a civil war despite the fact that it was certain to cause a bloodbath.

(c) (Obj_Nom) According to historians, that radical group was eager to start a civil war despite their acknowledgment of it to be folly.

(d) (Obj_Clause) According to historians, that radical group was eager to start a civil war despite the fact that they acknowledged it to be folly.

2. (a) (Subj_Nom) Studies have found that the name of a species affects its likelihood to become endangered.

(b) (Subj_Clause) Studies have found that the name of a species affects whether it is likely to become endangered.

(c) (Obj_Nom) Studies have found that the name of a species affects conservation groups' pronouncement of them to be endangered.

(d) (Obj_Clause) Studies have found that the name of a species affects whether conservation groups will pronounce them to be endangered.

3. (a) (Subj_Nom) The litigants were determined to go forward with the lawsuit despite its certainty to be a bitter and prolonged process.

(b) (Subj_Clause) The litigants were determined to go forward with the lawsuit despite the fact that it was certain to be a bitter and prolonged process.

(c) (Obj_Nom) The litigants were determined to go forward with the lawsuit despite their recognition of it to be a bitter and prolonged process.

(d) (Obj_Clause) The litigants were determined to go forward with the lawsuit despite the fact that they recognized it to be a bitter and prolonged process.

4. (a) (Subj_Nom) At the hearing, the government-appointed psychiatrist asserted that the defendant's likelihood to re-offend is low.

(b) (Subj_Clause) At the hearing, the government-appointed psychiatrist asserted that the defendant is not likely to re-offend.

(c) (Obj_Nom) At the hearing, the government-appointed psychiatrist asserted his estimation of the defendant to be unlikely to re-offend.

(d) (Obj_Clause) At the hearing, the government-appointed psychiatrist asserted that he estimated the defendant to be unlikely to re-offend. 
5. (a) (Subj_Nom) One state representative argued against the legislation on the basis of its certainty to increase consumer bills.

(b) (Subj_Clause) One state representative argued against the legislation on the basis of the fact that it was certain to increase consumer bills.

(c) (Obj_Nom) One state representative argued against the legislation on the basis of his calculation of it to be cost prohibitive.

(d) (Obj_Clause) One state representative argued against the legislation because he calculated it to be cost prohibitive.

6. (a) (Subj_Nom) One large-scale study of workplace environments found that whether or not a man was in a committed relationship had no influence on his likelihood to sexually harass.

(b) (Subj_Clause) One large-scale study of workplace environments found that whether or not a man was in a committed relationship had no influence on whether he was likely to sexually harass.

(c) (Obj_Nom) One large-scale study of workplace environments found that whether or not a man was in a committed relationship had no influence on the observation of him to be a harasser.

(d) (Obj_Clause) One large-scale study of workplace environments found that whether or not a man was in a committed relationship had no influence on whether anyone observed him to be a harasser.

7. (a) (Subj_Nom) Public opinion has shifted in favor of that country, perhaps because of its certainty to lose the war it began without provocation.

(b) (Subj_Clause) Public opinion has shifted in favor of that country, perhaps because it is certain to lose the war it began without provocation.

(c) (Obj_Nom) Public opinion has shifted in favor of that country, perhaps because of their presumption of it to be about to lose the war it began without provocation.

(d) (Obj_Clause) Public opinion has shifted in favor of that country, perhaps because they presume it to be about to lose the war it began without provocation.

8. (a) (Subj_Nom) Equity investors have revised their assessment of that company on the basis of their estimate of its likelihood to meet its debt obligations.

(b) (Subj_Clause) Equity investors have revised their assessment of that company on the basis of their estimate that it is likely to meet its debt obligations.

(c) (Obj_Nom) Equity investors have revised their assessment of that company on the basis of their calculation of it to be able to meet its debt obligations.

(d) (Obj_Clause) Equity investors have revised their assessment of that company because they calculate it to be able to meet its debt obligations. 